\title{
Concurrent central diabetes insipidus and cerebral salt wasting disease in a post- operative case of craniopharyngioma: a case report
}

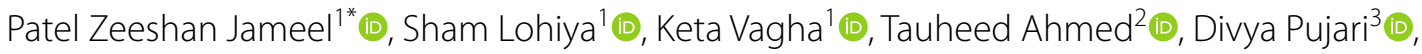 \\ Jayant Vagha' ${ }^{1}$ and Ashish Varma ${ }^{1}$ (i)
}

\begin{abstract}
Background: Water and electrolyte disorders commonly encountered in children post-surgery involving hypothalamus and posterior pituitary, are central diabetes insipidus, syndrome of inappropriate secretion of anti-diuretic hormone and cerebral salt wasting disease. Delayed diagnosis and inadequate management of such cases may lead to worsened neurological outcomes with a high mortality rate.

Case presentation: Here we report the case of a 7-year-old girl who underwent surgical resection of a craniopharyngioma, following which she initially developed central diabetes insipidus. However, later on in the course of her illness she developed symptomatic hyponatremia with natriuresis which was diagnosed to be due to cerebral salt wasting disease. This combination of central diabetes insipidus and cerebral salt wasting syndrome is a rare occurrence and poses a diagnostic challenge. Diagnosis and management can be even more difficult when these conditions precede or coexist with each other.

Conclusion: In such cases development of hyponatremia should always prompt consideration of unusual causes like cerebral salt wasting disease in addition to the classically described syndrome of inappropriate secretion of anti-diuretic hormone. Hence, a thorough knowledge of these disorders along with intensive monitoring of fluid and sodium status is critical for timely diagnosis and management of these patients.
\end{abstract}

Keywords: Central diabetes insipidus, Cerebral salt wasting disease, Craniopharyngioma

\section{Background}

Fluid and electrolyte imbalance is commonly encountered in children secondary to central nervous system (CNS) insult. Among children undergoing surgeries in the sellar and suprasellar regions, most commonly due to craniopharyngioma, the incidence of fluid and electrolyte disorders is quite high. Central diabetes insipidus (CDI),

\footnotetext{
${ }^{*}$ Correspondence: zeeshan1311@gmail.com

${ }^{1}$ Department of Paediatrics, Jawaharlal Nehru Medical College, Sawangi

(Meghe), Wardha, Maharashtra 442001, India

Full list of author information is available at the end of the article
}

syndrome of inappropriate antidiuretic hormone secretion (SIADH), cerebral salt wasting (CSW) disease and adipsic diabetes insipidus (ADI) can occur individually or exist simultaneously making their diagnosis and management extremely troublesome.

Here, we present the case of a female child with CDI and CSW disease occurring simultaneously after surgical resection of craniopharyngioma. 


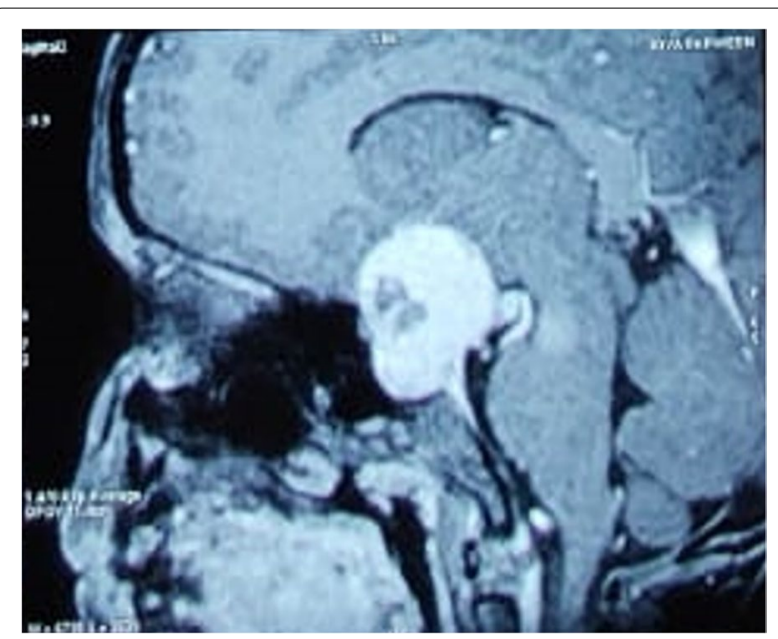

Fig. 1 T1W image showing iso to hyperintense mass involving the sella and suprasellar region

\section{Case presentation}

A 7-year-old girl presented with complaints of headache for the past 1 month and progressive right sided weakness for the past 15 days. On examination, the child had right sided hemiplegia, bilateral hemianopia and signs of optic atrophy in both eyes. MRI brain showed a $3 \times 2 \times 0.5 \mathrm{~cm}$ large sellar and supra-sellar mass with $\mathrm{T} 1$ weighted image showing iso to hyperintense lesion suggestive of a craniopharyngioma (Fig. 1). Pre-operative hormonal levels $(\mathrm{GH}, \mathrm{TSH}$, free T4, $8 \mathrm{AM}$ cortisol, FSH, $\mathrm{LH}$ and prolactin) were within normal limits. She underwent gross total resection of the tumor by left frontotemporal craniotomy. As the tumor was infiltrating the pituitary stalk, it had to be sacrificed along with the infundibulum.

Following surgery, she developed polyuria and her urine output was $8 \mathrm{ml} / \mathrm{kg} / \mathrm{hr}$. Further investigations showed elevated serum sodium $(156 \mathrm{mEq} / \mathrm{L})$, raised plasma osmolality $(321 \mathrm{mOsm} / \mathrm{kg})$ and decreased urinary osmolality $(175 \mathrm{mOsm} / \mathrm{kg})$. Her blood sugars were within normal limits $(122-140 \mathrm{mg} / \mathrm{dL})$. She was diagnosed to be suffering from CDI. Fluid losses in excess of the normal maintenance fluid rate were replaced volume for volume with $0.9 \%$ normal saline 6 hourly. She was started on IV dexamethasone $(0.2 \mathrm{mg} / \mathrm{kg} /$ day; 6 hourly $)$ and subcutaneous vasopressin (4IU/day; 6 hourly). Urine output and serum sodium levels were strictly monitored. She also complained of no light perception in both of her eyes. On the second post-operative day, she continued to have polyuria although a decrease was observed from the previous day $(7 \mathrm{ml} / \mathrm{kg} / \mathrm{hr})$. Sodium levels increased to $160 \mathrm{mEq} / \mathrm{L}$. The dose of vasopressin was increased further (6IU/day) and administered when required after she had episodes of breakthrough polyuria. By the third postoperative day, her urine output had stabilized at around $3-4 \mathrm{ml} / \mathrm{kg} / \mathrm{hr}$. and her sodium levels were between 136 and $143 \mathrm{mEq} / \mathrm{L}$. Her subcutaneous dose was changed to oral desmopressin $(0.1 \mathrm{mg} /$ day $)$ twice daily. Oral dosage was also regulated as per her urine output with daily monitoring of serum sodium levels. On the seventh postoperative day, hormonal profile was suggestive of hypocortisolism (8 AM plasma cortisol: $1.47 \mu \mathrm{g} / \mathrm{dL}$ ) and central hypothyroidism (TSH: $0.44 \mathrm{mIU} / \mathrm{L}$, Free T4: $0.44 \mathrm{ng} / \mathrm{dL}$ ). She was started on levothyroxine $25 \mathrm{mcg}$. In addition, as the dexamethasone was stopped by fifth post-operative day, she was started on hydrocortisone $1.25 \mathrm{mg}(10 \mathrm{mg} /$ $\mathrm{m}^{2} /$ day) 6 hourly.

On the ninth post-operative day, her mother noticed polyuria and irritability. In view of her polyuria, increasing the dose of desmopressin further was considered but was not done as the serum sodium was $132 \mathrm{mEq} / \mathrm{L}$. Fluid losses in excess of the normal maintenance fluid rate was replaced volume for volume with $0.9 \%$ normal saline 6 hourly. However, there was no relief in her symptoms. In addition, on the tenth post-operative day, she was became increasingly drowsy. Her repeat serum sodium was $127 \mathrm{mEq} / \mathrm{L}$. There was a rise in hemoglobin and hematocrit as well. Desmopressin was withheld. A paired plasma osmolality was $261 \mathrm{mOsm} / \mathrm{kg}$ and urinary osmolality was $615 \mathrm{mOsm} / \mathrm{kg}$. Her urinary sodium was $218 \mathrm{mEq} / \mathrm{L}$ despite having hyponatremia. Repeat serum urea, BUN, serum creatinine and serum potassium were within normal limits for her age. Her blood glucose was also normal. A diagnosis of CSW was thus made. A single bolus of hypertonic saline $(3 \% \mathrm{NaCl})$ was administered over 20-30 min followed by a continuous infusion in view of symptomatic hyponatremia. Tab fludrocortisone was started at $0.1 \mathrm{mg} /$ day. Hypertonic saline infusion was tapered and stopped after $12 \mathrm{~h}$ as sodium levels normalized. Over the next 2 days, serum osmolality $(292 \mathrm{mOsm} /$ $\mathrm{kg})$ and urinary osmolality $(300 \mathrm{mOsm} / \mathrm{kg})$ had normalized along with a reduction in urinary sodium level $(25 \mathrm{mEq} / \mathrm{L})$. Her sensorium had improved but polyuria persisted. Desmopressin was restarted $(0.1 \mathrm{mg} /$ day $)$ once the sodium level had normalized as polyuria was due to CDI. Given the above clinical scenario, an overlap of CDI and CSW disease was considered in the present case. Figure 2 summarizes the changes in urine output and serum sodium levels throughout the period of her hospital stay. Over the next couple of days, her desmopressin dose was adjusted and fludrocortisone was reduced to $0.05 \mathrm{mg} /$ day. Tab. Fludrocortisone was later tapered and stopped after 7 days. She was discharged after 20 days of hospital stay on hydrocortisone, levothyroxine and desmopressin.

On follow-up after 2 weeks, her hormonal profile showed low TSH (0.52 mIU/L), normal free T4 (1.22 ng/ 


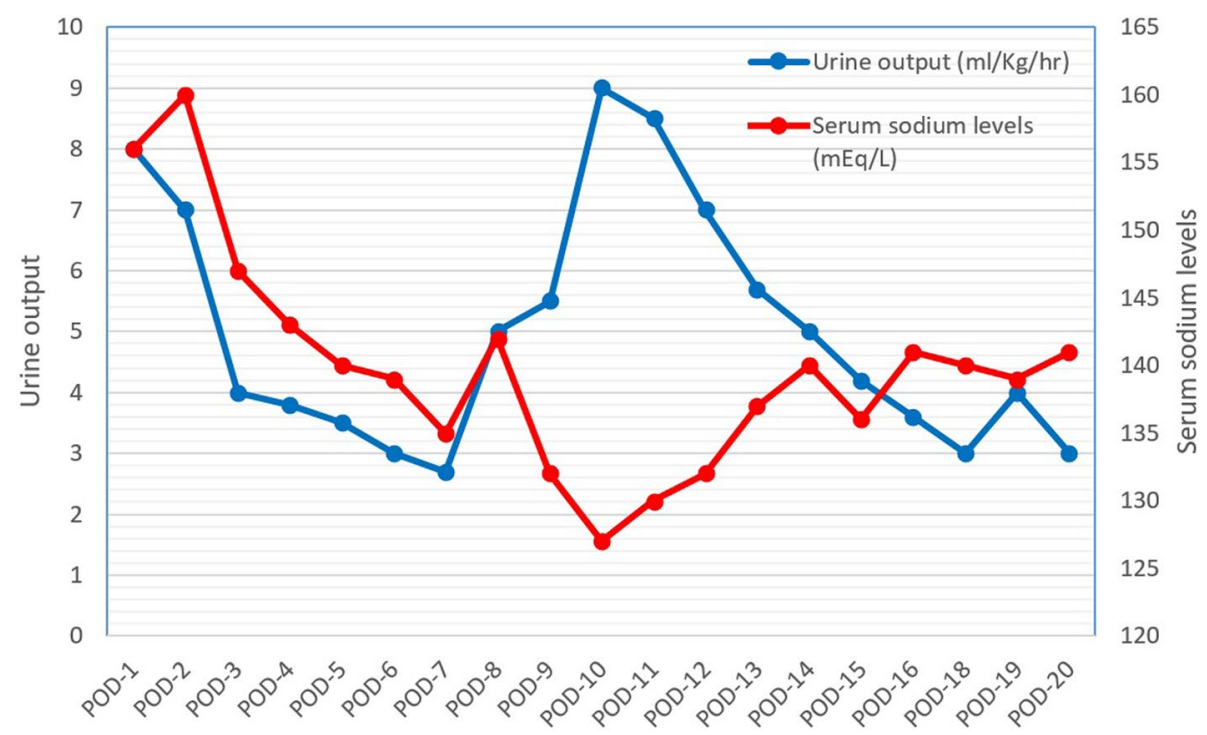

Fig. 2 Trend of urine output (blue) and serum sodium levels (red) through the post-op period. Initially, a phase of diuresis [U/O: $8 \mathrm{ml} / \mathrm{kg}^{\prime} / \mathrm{hr} ; \mathrm{Sr} \mathrm{Na}{ }^{+}$: $156 \mathrm{mEq} / \mathrm{L}$ ] was followed by a phase of natriuresis and hyponatremia by the 10th post-operative day due to CSW disease [U/O: $9 \mathrm{ml} / \mathrm{kg} / \mathrm{hr} ; ; \mathrm{Sr} \mathrm{Na}{ }^{+}$: $127 \mathrm{mEq} / \mathrm{L}]$. The final stage was permanent diabetes insipidus after waning of CSW disease. POD: Post-operative day, U/O: Urine output; Sr Na+: serum sodium level

$\mathrm{dL})$ and low $8 \mathrm{AM}$ cortisol $(4.1 \mathrm{mcg} / \mathrm{dL})$ requiring increase in dosages of levothyroxine to $37.5 \mathrm{mcg} /$ day and tab. Hydrocortisone to $2.5 \mathrm{mg}\left(10 \mathrm{mg} / \mathrm{m}^{2} /\right.$ day $) 8$ hourly. Serum sodium and potassium levels were normal for her age. After 2 weeks, a repeat hormonal profile (TSH, free T4 and $8 \mathrm{AM}$ cortisol) was within normal limits. She is now clinically well with her permanent DI under control on $0.15 \mathrm{mg} /$ day of desmopressin. As part of her neurological morbidity, she has hemiparesis with no improvement in power and has only light perception in both eyes.

\section{Discussion and conclusion}

Central nervous system (CNS) performs a crucial role in the maintenance of water and sodium homeostasis resulting from a complex interplay between hypothalamus, posterior pituitary, and adrenal glands. Factors disrupting the regulation of this normal HPA axis result in pathological conditions such as CDI, SIADH and CSW disease. Craniopharyngiomas account for 6-9\% of brain tumors in children [1]. Endocrine dysfunction is a well-known complication arising from surgical or radiation treatment of craniopharyngioma [1]. Children were found to be particularly vulnerable to pituitary hormonal deficiency post-surgery. Incidence of a single or multiple pituitary hormone deficiency can range from 36 to $98 \%$ after surgery [2-6]. In addition to this, the incidence of water and sodium related disorders in children undergoing surgeries involving sellar and supra-sellar region varies from 40 to $72 \%[7,8]$.
Post-pituitary surgery hyponatremia is commonly encountered and carries a wide spectrum of differential diagnosis such as improper fluid administration, hypocortisolism, hypothyroidism, over-correction of DI in over-dosing of desmopressin, SIADH and CSW disease. Hypocortisolism may lead to hyponatremia by causing an increase in ADH levels along with impaired renal free water excretion $[7,9]$. To prevent this hydrocortisone should be started at $10-12 \mathrm{mg} / \mathrm{m}^{2} / \mathrm{kg}$ (in $3-4$ divided doses) preferably pre-operatively although a steroid sparing approach may also be used where steroids are only started when hypocortisolism is present [10]. In cases where the child is already on dexamethasone, no additional hydrocortisone is required. Post-surgery, dexamethasone should be carefully tapered along with a parallel increase in dose of hydrocortisone.

Central diabetes insipidus (CDI) results from a deficiency of arginine vasopressin (AVP), and is characterized clinically by polyuria, polydipsia, and dehydration [11-13]. CDI has been reported in upto $80 \%$ of children post-surgery [13]. Pathologic polyuria $(>4 \mathrm{ml} / \mathrm{kg} / \mathrm{hr}$ ) with raised serum osmolality $(>300 \mathrm{mOsm} / \mathrm{kg})$ and hypernatremia $(>145 \mathrm{mEq} / \mathrm{L})$ but decreased urine osmolality $(<300 \mathrm{mOsm} / \mathrm{kg})$ with low urine specific gravity $(<1.010)$ establishes a diagnosis of CDI [11-13]. It is essential to rule out hyperglycemia and cortisol deficiency prior to establishing a diagnosis of CDI. Injury to the pituitary stalk during surgery or head injury can lead to a transient, triphasic or permanent CDI. Transient CDI can 
manifest within hours of surgery with polyuria lasting for 5-7 days. It usually settles once the AVP secreting neurons located in the posterior pituitary recover their normal function. In the triphasic response, the first phase of transient CDI is followed by second phase of SIADH resulting from an unregulated release of $\mathrm{ADH}$ from the dying or damaged axons in posterior pituitary. SIADH is characterized by oliguria, decreased serum osmolality $(<280 \mathrm{mOsm} / \mathrm{kg})$, hyponatremia $(<135 \mathrm{mEq} / \mathrm{L})$, urine osmolality $(>100 \mathrm{mOsm} / \mathrm{kg})$ and urine sodium excretion of $>30 \mathrm{mEq} / \mathrm{L}[14,15]$. Usually, after about 2 weeks, reemergence of polyuria marks the onset of third phase of permanent $\mathrm{CDI}$ resulting from the death of $\mathrm{ADH}$ secreting neurons [16].

In addition to these presentations, rarely patient might develop CSW disease due to a primary neuronal insult or as a secondary response to SIADH [16]. CSW disease has been hypothesized to result either from increased levels of natriuretic peptides, especially BNP, or due to a poor sympathetic outflow to kidneys [15]. CSW disease was first described by Peters et al. in 3 patients with neurological disorder and hyponatremia $[15,17]$. However, for the following 20 years, CSW disease was an under-recognized entity until Nelson et al. [18] conclusively demonstrated volume depletion and hyponatremia with increased urinary sodium excretion consistent with CSW disease pathogenesis. CSW disease can occur secondary to any form of CNS insult such as head trauma, stroke, subarachnoid hemorrhage, hydrocephalus, TB meningitis, or even post-operatively after resection of brain tumors [19-21]. Diagnosis of an underlying CSW disease in children can be established in the presence of elevated urinary sodium excretion $(>120 \mathrm{mEq} / \mathrm{L})$ and urine osmolality $(>300 \mathrm{mOsm} /$ $\mathrm{kg})$ despite the child having polyuria $(\geq 3-4 \mathrm{ml} / \mathrm{kg} /$ $\mathrm{hr})$, dehydration, hyponatremia $(<130 \mathrm{mEq} / \mathrm{L})$ and a negative $24 \mathrm{~h}$ fluid balance $[19,20]$. Incidence of CSW disease in post-operative cases of brain tumor among children has been observed to be more common than SIADH, contrary to previous belief. González Briceño L et al. [7] found CSW disease to be more common (3.8\% vs $1.3 \%$ ) than SIADH on follow-up post-surgery of suprasellar tumors in children. Similarly, Hardesty DA et al. [22] also observed CSW disease in 5\% of post-op children as compared to $3 \%$ of SIADH cases. Another study by Williams CN et al. [23] observed CSW disease more common than SIADH ( $44 \%$ vs $26 \%$ ) in post-op cases of brain tumor. In addition, identified risk factors include younger age ( $\leq 7$ years) and female sex [23]. SIADH and CSW disease both have similar biochemical laboratory parameters such as low serum osmolality, high urine osmolality and natriuresis. Despite the similarities, natriuresis is considerably higher than the sodium intake in CSW while it is more or less equal in SIADH. In addition to this, SIADH patients have a state of euvolemia or mild extracellular fluid expansion while patients CSW disease are dehydrated with a negative fluid balance due to severe natriuresis [16]. Both SIADH and CSW disease present with post-operative hyponatremia. In all such cases, hypocortisolism and hypothyroidism need to be excluded. An early peri-operative glucocorticoid replacement, in addition to preventing/correcting hyponatremia, also helps to reduce cerebral edema.

The coexistence of CDI and CSW disease is extremely rare, rather CDI is associated with SIADH especially in operated patients of sellar and supra-sellar tumors. Combined CDI and CSW disease has been reported in patients suffering from traumatic brain injury, cardiac arrest, cardiogenic and septic shock, meningitis, encephalitis, shaken baby syndrome, intracranial hemorrhage, sellar and/or supra-sellar tumors [19, 24-27]. Prognosis in all of these cases was found to variable and dependent upon the underlying cause as well as effective treatment of both CDI and CSW disease. In our case, child had initially developed CDI, however, in stark contrast to the classically described 'triphasic response', our patient developed CSW disease after an initial phase of CDI. SIADH and CSW disease can be particularly difficult to differentiate as both present with hyponatremia. The measurement of fluid input, urine output, serum osmolality, and urine osmolality helps to differentiate CSW disease from SIADH. In our case as well, increased urinary osmolality and increased urinary sodium excretion despite the child having hyponatremia, dehydration and decreased serum osmolality guided us to consider CSW disease over SIADH. CSW disease was a transient event as it responded quite well to fludrocortisone and ultimately the drug was stopped. Later on, she was maintained on levothyroxine, hydrocortisone and desmopressin for managing her hypothyroidism, hypocortisolism and diabetes insipidus.

To conclude, in cases of CDI following surgery, development of hyponatremia should always prompt consideration of unusual causes like CSW in addition to the classically described SIADH. Early recognition and differentiation of CSW disease from SIADH is important, as management strategies for these conditions are completely different, and a misdiagnosis or even a delay in diagnosis can prove fatal. Prompt diagnosis and appropriate management of CDI and CSW disease was extremely crucial in the survival of our patient. We therefore recommend a close watch on serum sodium, and urine output in all operated cases of sellar/suprasellar tumors, with a low threshold for measuring urinary sodium excretion, urine osmolality and serum osmolality. 


\section{Learning points}

- A triphasic response in not necessarily the rule of thumb in operated cases involving the pituitary stalk.

- A greater emphasis is required on the importance of close monitoring after pituitary stalk injury postsurgery to prevent further endocrine morbidity and mortality.

\begin{abstract}
Abbreviations
CNS: Central nervous system; CDI: Central diabetes insipidus; CSW: Cerebral salt wasting; SIADH: Syndrome of inappropriate antidiuretic hormone secretion; MRI: Magnetic resonance imaging; GH: Growth hormone; TSH: Thyroid stimulating hormone; FSH: Follicle stimulating hormone; LH: Luteinizing hormone; HPA: Hypothalamo-pituitary-adrenal; AVP: Arginine vasopressin.
\end{abstract}

\section{Acknowledgements}

We wish to thank the pediatricians involved in the care of the patients including Dr. Gnyanavellu Injeti, Dr. Sachin Yedve and Dr. Parameshwar Reddy.

\section{Authors' contributions}

PZJ and TA drafted the initial manuscript, performed the relevant literature search, critical review and revision of the manuscript. SL was involved in patient management, data collection and revision of the manuscript. DP was involved in drafting the initial manuscript, patient's data collection, critical review and revision of the manuscript. AV, KV and JV supervised the data collection, critically reviewed and revised the manuscript. All authors have read and approved the manuscript.

\section{Authors' information}

Already included.

\section{Funding}

Not applicable.

\section{Availability of data and materials}

The datasets used and/or analyzed during the current study are available from the corresponding author on reasonable request.

\section{Declarations}

\section{Ethics approval and consent to participate}

The authors certify that they have obtained all appropriate patient consent forms. In the form the patient's parents have given their consent for patient's images and other clinical information to be reported in the journal. The patient's parents understand that their names and initials will not be published and due efforts will be made to conceal their identity, but anonymity cannot be guaranteed.

\section{Consent for publication}

Written informed consent was obtained from the patient's parents for publication of this case report and any accompanying images and videos. A copy of the written consent is available for review by the Editor-in-Chief of this journal.

\section{Competing interests}

The authors declare that they have no competing interests.

\section{Author details}

${ }^{1}$ Department of Paediatrics, Jawaharlal Nehru Medical College, Sawangi (Meghe), Wardha, Maharashtra 442001, India. ${ }^{2}$ Department of Medicine, Tata Main Hospital, Jamshedpur, Jharkhand, India. ${ }^{3}$ Division of Paediatric Endocrinology, Department of Paediatrics, Bai Jerbai Wadia Hospital for Children, Mumbai, Maharashtra, India.
Received: 10 August 2021 Accepted: 29 October 2021

Published online: 10 November 2021

\section{References}

1. Drapeau A, Walz P, Eide J, Rugino A, Shaikhouni A, Mohyeldin A, et al. Pediatric craniopharyngioma. Childs Nerv Syst ChNS Off J Int Soc Pediatr Neurosurg. 2019;35(11) Available from: https://pubmed.ncbi.nlm.nih.gov/ 31385085/. Cited 2021 Jun 4.

2. Koumas C, Laibangyang A, Barron SL, Mittler MA, Schneider SJ, Rodgers SD. Outcomes following endoscopic endonasal resection of sellar and supresellar lesions in pediatric patients. Childs Nerv Syst ChNS Off J Int Soc Pediatr Neurosurg. 2019;35(11):2099-105.

3. Wijnen M, van den Heuvel-Eibrink MM, Janssen JAMJL, Catsman-Berrevoets CE, Michiels EMC, van Veelen-Vincent M-LC, et al. Very long-term sequelae of craniopharyngioma. Eur J Endocrinol. 2017;176(6):755-67.

4. Koutourousiou M, Gardner PA, Fernandez-Miranda JC, Tyler-Kabara EC, Wang EW, Snyderman CH. Endoscopic endonasal surgery for craniopharyngiomas: surgical outcome in 64 patients. J Neurosurg. 2013;119(5):1194-207.

5. Patel VS, Thamboo A, Quon J, Nayak JV, Hwang PH, Edwards M, et al. Outcomes after endoscopic endonasal resection of craniopharyngiomas in the pediatric population. World Neurosurg. 2017:108:6-14.

6. Jazbinšek S, Kolenc D, Bošnjak R, Faganel Kotnik B, Zadravec Zaletel L, Jenko Bizjan B, et al. Prevalence of endocrine and metabolic comorbidities in a National Cohort of patients with craniopharyngioma. Horm Res Paediatr. 2020;93(1):46-57.

7. González Briceño L, Grill J, Bourdeaut F, Doz F, Beltrand J, Benabbad l, et al. Water and electrolyte disorders at long-term post-treatment follow-up in paediatric patients with suprasellar tumours include unexpected persistent cerebral salt-wasting syndrome. Horm Res Paediatr. 2014:82(6):364-71.

8. Saldarriaga C, Lyssikatos C, Belyavskaya E, Keil M, Chittiboina P, Sinaii N, et al. Postoperative diabetes insipidus and hyponatremia in children after transsphenoidal surgery for adrenocorticotropin hormone and growth hormone secreting adenomas. J Pediatr. 2018;195:169-174.e1.

9. Reynolds RM, Seckl JR. Hyponatraemia for the clinical endocrinologist Clin Endocrinol. 2005:63(4):366-74.

10. Prete A, Corsello SM, Salvatori R. Current best practice in the management of patients after pituitary surgery. Ther Adv Endocrinol Metab. 2017:8(3):33-48.

11. Dabrowski E, Kadakia R, Zimmerman D. Diabetes insipidus in infants and children. Best Pract Res Clin Endocrinol Metab. 2016;30(2):317-28.

12. Weiner A, Vuguin P. Diabetes insipidus. Pediatr Rev. 2020;41(2):96-9.

13. Iorgi ND, Napoli F, Allegri AEM, Olivieri I, Bertelli E, Gallizia A, et al. Diabetes insipidus - diagnosis and management. Horm Res Paediatr. 2012;77(2):69-84

14. Moritz ML. Syndrome of inappropriate antidiuresis. Pediatr Clin N Am. 2019:66(1):209-26.

15. Oh JY, Shin J. Syndrome of inappropriate antidiuretic hormone secretion and cerebral/renal salt wasting syndrome: similarities and differences. Front Pediatr. 2015;2 Available from: https://www.frontiersin.org/articles/ 10.3389/fped.2014.00146/full. Cited 2021 Jun 10

16. Edate S, Albanese A. Management of electrolyte and fluid disorders after brain surgery for pituitary/suprasellar tumours. Horm Res Paediatr. 2015:83(5):293-301.

17. Peters J, Welt L, Sims E, Orloff J, Needham J. A salt-wasting syndrome associated with cerebral disease. Trans Assoc Am Phys. 1950;63:57-64.

18. Nelson PB, Seif SM, Maroon JC, Robinson AG. Hyponatremia in intracranial disease: perhaps not the syndrome of inappropriate secretion of antidiuretic hormone (SIADH). J Neurosurg. 1981;55(6):938-41.

19. Lin J-J, Lin K-L, Hsia S-H, Wu C-T, Wang H-S. Combined central diabetes insipidus and cerebral salt wasting syndrome in children. Pediatr Neurol. 2009;40(2):84-7.

20. Jiménez R, Casado-Flores J, Nieto M, García-Teresa MA. Cerebral salt wasting syndrome in children with acute central nervous system injury. Pediatr Neurol. 2006;35(4):261-3.

21. Celik U, Celik T, Tolunay O, Başpınar H, Kömür M, Levent F. Cerebral salt wasting in tuberculous meningitis: two cases and review of the literature. Case report. Neuro Endocrinol Lett. 2015;36(4):306-10. 
22. Hardesty DA, Kilbaugh TJ, Storm PB. Cerebral salt wasting syndrome in post-operative pediatric brain tumor patients. Neurocrit Care. 2012;17(3):382-7.

23. Williams CN, Riva-Cambrin J, Bratton SL. Etiology of postoperative hyponatremia following pediatric intracranial tumor surgery. J Neurosurg Pediatr. 2016;17(3):303-9.

24. Wu X, Zhou X, Gao L, Wu X, Fei L, Mao Y, et al. Diagnosis and management of combined central diabetes insipidus and cerebral salt wasting syndrome after traumatic brain injury. World Neurosurg. 2016:88:483-7.

25. Costa MM, Esteves C, Castedo JL, Pereira J, Carvalho D. A challenging coexistence of central diabetes insipidus and cerebral salt wasting syndrome: a case report. J Med Case Rep. 2018;12(1):212.

26. Kurtoğlu S, Atabek ME, Keskin M, Patiroglu T, Kumandas S, Topaloglu N. Rhabdomyosarcoma with coexistent diabetes insipidus and cerebral salt wasting as postoperative complication. Pediatr Int Off J Jpn Pediatr Soc. 2006;48(1):79-81.

27. Sano S, Yamagami K, Morikawa T, Yoshioka K. Myelodysplastic syndrome complicated by central diabetes insipidus and cerebral salt wasting syndrome with peculiar change in magnetic resonance images. Intern Med Tokyo Jpn. 2010;49(2):161-5.

\section{Publisher's Note}

Springer Nature remains neutral with regard to jurisdictional claims in published maps and institutional affiliations.
Ready to submit your research? Choose BMC and benefit from:

- fast, convenient online submission

- thorough peer review by experienced researchers in your field

- rapid publication on acceptance

- support for research data, including large and complex data types

- gold Open Access which fosters wider collaboration and increased citations

- maximum visibility for your research: over $100 \mathrm{M}$ website views per year

At BMC, research is always in progress.

Learn more biomedcentral.com/submissions 